\title{
Effects of Fostamatinib on the Pharmacokinetics of Oral Contraceptive, Warfarin, and the Statins Rosuvastatin and Simvastatin: Results From Phase I Clinical Studies
}

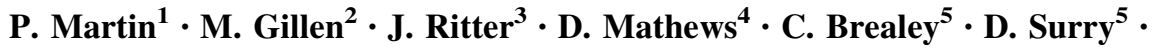 \\ S. Oliver ${ }^{1} \cdot$ V. Holmes ${ }^{6} \cdot$ P. Severin ${ }^{7} \cdot$ R. Elsby ${ }^{1}$
}

Published online: 9 January 2016

(c) The Author(s) 2016. This article is published with open access at Springerlink.com

\begin{abstract}
Background and objectives Fostamatinib is a spleen tyrosine kinase inhibitor that has been investigated as therapy for rheumatoid arthritis and immune thrombocytopenic purpura. The present studies assessed the potential for pharmacokinetic interaction between fostamatinib and the commonly prescribed medications oral contraceptive (OC), warfarin, and statins (rosuvastatin, simvastatin) in healthy subjects.

Methods The OC study was a crossover study over two 28-day treatment periods (Microgynon ${ }^{\circledR} 30$ plus placebo or fostamatinib). Concentrations of OC constituents (ethinyl estradiol/levonorgestrel) were measured. Effects on warfarin pharmacokinetics and pharmacodynamics were assessed (21-day study). Warfarin was administered on
\end{abstract}

Electronic supplementary material The online version of this article (doi:10.1007/s40268-015-0120-x) contains supplementary material, which is available to authorized users.

\footnotetext{
M. Gillen

Michael.gillen@astrazeneca.com

P. Martin

paul.martin@astrazeneca.com

1 AstraZeneca Pharmaceuticals, Alderley Park, SK10 4TF Macclesfield, Cheshire, UK

2 AstraZeneca, Wilmington, DE, USA

3 Quintiles Drug Research Unit, Guy's Hospital, London, UK

4 Quintiles Phase I Unit, 6700 W 115th St, Overland Park, KS, USA

5 Former-AstraZeneca, Macclesfield, Cheshire, UK

6 AstraZeneca, Cambridge, Cambridgeshire, UK

7 Covance, Madison, WI, USA
}

days 1 and 14, fostamatinib on days 8-20. The statin study was a two-period, fixed-sequence study of the effects of fostamatinib on exposure to rosuvastatin or simvastatin (single doses). Safety was assessed throughout.

Results Fostamatinib co-administration with OC increased exposure to ethinyl estradiol [area under the plasma concentration-time curve at steady state $\left(\mathrm{AUC}_{\mathrm{ss}}\right)$ $28 \%$ [confidence interval (CI $90 \%$ ) 21-36]; maximum plasma concentration $\left(C_{\max }\right)$ at steady state $\left(C_{\max , \mathrm{ss}}\right) 34 \%$ (CI 26-43)], but not levonorgestrel $\left(\mathrm{AUC}_{\mathrm{ss}} 5 \%\right.$; $C_{\mathrm{max}, \mathrm{ss}}$ $-3 \%$ ), while exposure to luteinizing hormone and folliclestimulating hormone decreased $(\approx 20 \%)$. Fostamatinib did not affect the pharmacokinetics/pharmacodynamics of warfarin to a clinically relevant extent, but caused an upward trend in AUC for both $R$ - and $S$-warfarin [18\% (CI 13-23) and $13 \%$ (CI 7-19)]. Fostamatinib increased rosuvastatin AUC by $96 \%$ (CI 78-115) and $C_{\max }$ by $88 \%$ (CI 69-110), and increased simvastatin acid AUC by $74 \%$ (CI 50-102) and $C_{\max }$ by $83 \%$ (CI 57-113).

Conclusion Fostamatinib exhibits drug-drug interactions when co-administered with OC, simvastatin, or rosuvastatin, with the AUC of statins almost doubling. Fostamatinib did not exhibit a clinically relevant DDI on warfarin.

\footnotetext{
Abbreviations

AE Adverse event

APCI Atmospheric pressure chemical ionization

AUC Area under the plasma concentration-time curve from zero to infinity

$\mathrm{AUC}_{\mathrm{INR}, 0-168}$ Area under the international normalized ratio-time curve from zero to $168 \mathrm{~h}$ after dose

$\mathrm{AUC}_{\mathrm{ss}} \quad$ Area under the plasma concentration-time curve during the dosing interval at steady state
} 


\begin{tabular}{|c|c|}
\hline $\mathrm{AUC}_{t}$ & $\begin{array}{l}\text { Area under the plasma concentration-time } \\
\text { curve from zero to the time of the last } \\
\text { measurable concentration }\end{array}$ \\
\hline $\mathrm{AUC}_{\tau}$ & $\begin{array}{l}\text { Area under the plasma concentration-time } \\
\text { curve during a dosage interval }(\tau)\end{array}$ \\
\hline BCRP & Breast cancer resistance protein \\
\hline Bid & Twice daily \\
\hline CI & Confidence interval \\
\hline$C_{\max }$ & Maximum plasma concentration \\
\hline$C_{\max , \mathrm{ss}}$ & $\begin{array}{l}\text { Maximum plasma concentration at steady } \\
\text { state }\end{array}$ \\
\hline CYP3A4 & Cytochrome P450 3A4 \\
\hline DDI & Drug drug interaction \\
\hline EDTA & Ethylenediaminetetraacetic acid \\
\hline ELISA & Enzyme linked immune sorbent assay \\
\hline FSH & Follicle-stimulating hormone \\
\hline HMG-CoA & 3-hydroxy-3-methyl-glutaryl coenzyme A \\
\hline $\mathrm{IC}_{50}$ & Half maximal inhibitory concentration \\
\hline INR & International normalized ratio \\
\hline $\mathrm{INR}_{\max }$ & Maximum international normalized ratio \\
\hline IRB & Institutional review board \\
\hline LC & Liquid chromatography \\
\hline LH & Luteinizing hormone \\
\hline LS & Least squares \\
\hline MS/MS & Tandem mass spectrometry \\
\hline OATP & Organic anion-transporting polypeptide \\
\hline $\mathrm{OC}$ & Oral contraceptive \\
\hline RA & Rheumatoid arthritis \\
\hline SD & Standard deviation \\
\hline SHBG & Sex hormone-binding globulin \\
\hline SLE & Supported liquid extraction \\
\hline TEA & Tri ethyl amine \\
\hline$t_{1 / 2 \lambda z}$ & Terminal half-life \\
\hline$t_{\max }$ & Time to $C_{\max }$ \\
\hline$t_{\mathrm{max}, \mathrm{ss}}$ & Time to $C_{\max }$ at steady state \\
\hline UGT & $\begin{array}{l}\text { Uridine 5'-diphospho- } \\
\text { glucuronosylttansferase }\end{array}$ \\
\hline
\end{tabular}

\section{Introduction}

Fostamatinib is an orally dosed inhibitor of spleen tyrosine kinase [1]. It has been investigated in patients with rheumatoid arthritis (RA) [2-6], and is currently under development for immune thrombocytopenic purpura [7, 8] and immunoglobulin A nephropathy [9].

The metabolism of fostamatinib involves dephosphorylation of the prodrug (R788) in the gastrointestinal tract to produce the active metabolite, R406 [1]. Understanding the pharmacologic interactions of fostamatinib and R406 is important when considering other commonly reported comorbidities in patients with RA (e.g., dyslipidemia and cardiovascular disease [10-12]. Polypharmacy is common in these individuals, predisposing them to drug-drug interactions [13]. We present three studies that investigated the influence of fostamatinib co-administration on the pharmacokinetics of oral contraceptive (OC), warfarin, and the 3-hydroxy-3-methyl-glutaryl coenzyme A (HMG-CoA) reductase inhibitors rosuvastatin and simvastatin.

Fostamatinib is metabolized by cytochrome P450 3A4 (CYP3A4), which it also inhibits in a time-dependent manner [1]. CYP3A4 is involved in the metabolism of OC. Fostamatinib is a substrate and inhibitor of uridine $5^{\prime}$ diphospho-glucuronosyltransferase (UGT), which is involved in the glucuronidation of estradiol [14]. RA is common in pre-menopausal women $[15,16]$. Therefore, our first study anticipated that co-administration of fostamatinib with an OC [Microgynon ${ }^{\circledR} 30$ (ethinyl estradiol and levonorgestrel; Bayer Pharma AG, Berlin, Germany)] would increase plasma ethinyl estradiol concentrations.

We also investigated the effects of fostamatinib on the pharmacokinetics of warfarin, an anticoagulant that is administered as a racemic mixture comprising equal amounts of $R$ - and $S$-warfarin [17, 18]. $S$-warfarin is a substrate of CYP2C9, and $R$-warfarin for CYP1A2, CYP2C19, and CYP3A4 [19]. Fostamatinib does not induce CYP1A2, CYP2C9, CYP2C19, or CYP3A4 [1], and therefore it was expected that fostamatinib would not reduce plasma warfarin concentrations or activity. However, due to the narrow therapeutic index of warfarin and its widespread use, it was important to confirm this experimentally.

Finally, we investigated the influence of fostamatinib on the pharmacokinetics of rosuvastatin and simvastatin. These statins are used to improve lipid profiles in patients at high risk for cardiovascular disease [20-22]. Rosuvastatin is a substrate of active transporters, including both organic anion-transporting polypeptide (OATP) 1B1 and breast cancer resistance protein (BCRP) [23-25], while simvastatin is metabolized by CYP3A4 and is a substrate of OATP1B1 [26, 27]. In vitro data show that both fostamatinib and R406 are potent inhibitors of BCRP [half maximal inhibitory concentration $\left(\mathrm{IC}_{50}\right) 0.050 \mu \mathrm{mol} / \mathrm{L}$ and $0.031 \mu \mathrm{mol} / \mathrm{L}$, respectively (AstraZeneca, data on file)]. R406 is a low-affinity substrate and weak inhibitor of OATP1B1 $\left[\mathrm{IC}_{50}\right.$ estimated at $>10 \mu \mathrm{mol} / \mathrm{L}$ (AstraZeneca, data on file)]. Current US Food and Drug Administration guidance [28] predicts that fostamatinib would increase systemic exposure to rosuvastatin through its inhibition of intestinal BCRP (theoretical gastrointestinal concentration/ $\mathrm{IC}_{50}>10$ ), rather than via OATP1B1, resulting in increased absorption. 


\section{Methods}

\subsection{Subject Populations}

All three studies (NCT01276262, NCT01311622, and NCT01725230) were performed in accordance with the principles of the Declaration of Helsinki [29] and the International Conference on Harmonisation/Good Clinical Practice [30]. All subjects gave written informed consent. Protocols for the OC and warfarin studies were reviewed by Capenhurst Independent Ethics Committee and the statin study by MidLands IRB.

The studies included healthy subjects aged $\geq 18$ years and with a body mass index of $\geq 18 \mathrm{~kg} / \mathrm{m}^{2}$. Subjects in the OC study had to be willing to use highly effective nonhormonal birth control such as double-barrier method contraception. Detailed inclusion and exclusion criteria are described in the Electronic Supplementary Material (Online Resource 1).

\subsection{Study Objectives}

The primary objective of the OC study was to assess the effect of repeated doses of fostamatinib on the pharmacokinetics of Microgynon ${ }^{\circledR} 30$ by assessment of its constituents, ethinyl estradiol and levonorgestrel, on day 21. Secondary objectives were to characterize the pharmacodynamics of progesterone, luteinizing hormone ( $\mathrm{LH})$, follicle-stimulating hormone (FSH), and sex hormone-binding globulin (SHBG) following dosing with Microgynon ${ }^{\circledR} 30$ alone and following co-administration with fostamatinib. For the warfarin study (warfarin supplied by Goldshield, Croydon, UK), the primary objective was to investigate whether $R$ - and $S$-warfarin plasma concentration-time profiles and resulting pharmacokinetic parameters (single administration) are altered during steady-state fostamatinib administration. This study also investigated the international normalized ratio (INR) after a warfarin administration, alone and with fostamatinib co-administration. The main objectives of the statin study were to assess the pharmacokinetics of rosuvastatin (AstraZeneca Pharmaceuticals LP, Wilmington, DE, USA) and simvastatin (Merck Sharp \& Dohme Ltd., Whitehouse Station, NJ, USA) when each was administered alone and in combination with fostamatinib.

Each study also evaluated the steady-state pharmacokinetics of the active metabolite R406 following co-administration of the respective investigational drugs with fostamatinib. Safety and tolerability of fostamatinib in combination with each drug were also examined.

\subsection{Study Design}

The OC study was a phase I, single-blind, placebo-controlled, two-period, fixed-sequence, crossover study that consisted of a $\leq 35$-day screening period followed by two treatment periods (28 days each) of Microgynon ${ }^{\circledR} 30$ (1 tablet/day comprising $30 \mu \mathrm{g}$ ethinyl estradiol and $150 \mu \mathrm{g}$ levonorgestrel) in the absence (treatment $\mathrm{A}=$ $\mathrm{OC}+$ placebo) and presence (treatment $\mathrm{B}=\mathrm{OC}+$ fostamatinib) of fostamatinib [100 mg twice daily (bid)] (Fig. 1a). The warfarin study was an open-label, non-randomized study during which warfarin $25 \mathrm{mg}$ was administered on days 1 and 14 of a 20-day treatment period along with fostamatinib $100 \mathrm{mg}$ bid on days $8-20$ (Fig. 1b). The statin study was an open-label, fixed-sequence study that assigned eligible subjects to receive either rosuvastatin $20 \mathrm{mg}$ (group A) or simvastatin $40 \mathrm{mg}$ (group B) over two treatment periods: alone for period 1 and in combination with fostamatinib (100 mg bid) for period 2 (Fig. 1c).

\subsubsection{Sample Collection and Bioanalysis}

For each period in the OC study, serial blood samples for pharmacokinetic analyses were collected before dose and periodically after dose, relative to OC administration on day 21 . In the warfarin study, pharmacokinetic and pharmacodynamic samples were collected before dose and periodically after dose relative to days 1 and 14 . For the statin study, blood samples were collected before dose and periodically after dose relative to day 1 in period 1 and day 6 in period 2. Details for sample collection in each study can be found in the Electronic Supplementary Material. In the statin study blood samples were taken from all subjects to collect DNA for extraction and investigation of variations in the genes encoding BCRP and OATP1B1 transporters, which are involved in rosuvastatin disposition.

All assays for R406, ethinyl estradiol, levonorgestrel, $R$ and $S$-warfarin, rosuvastatin, simvastatin, and simvastatin acid used deuterated internal standards and were analyzed by liquid chromatography (LC) with tandem mass spectrometric detection (MS/MS).

Ethinyl estradiol and levonorgestrel were analyzed in human plasma with K2EDTA anticoagulant.

The analytes were extracted with 1-chlorobutane. The organic phase was decanted and evaporated to dryness. The residue was derivatized with dansyl chloride and analyzed. The standard curve range was $7.50-500 \mathrm{pg} / \mathrm{mL}$ for ethinyl estradiol and $150-10,000 \mathrm{pg} / \mathrm{mL}$ for levonorgestrel for a $0.5 \mathrm{~mL}$ sample volume. LC analysis used a Phenomenex Onyx Monolithic C18 column, with a gradient mobile phase system (mobile phase A: $0.1 \%$ formic acid in water; mobile phase B: acetonitrile). Detection was by a Sciex API 5000 or QTRAP 5500 (positive ion electrospray ionization), with the transition monitored $530 \rightarrow 171$ for ethinyl estradiol and $313 \rightarrow 245$ for levonorgestrel. 
a

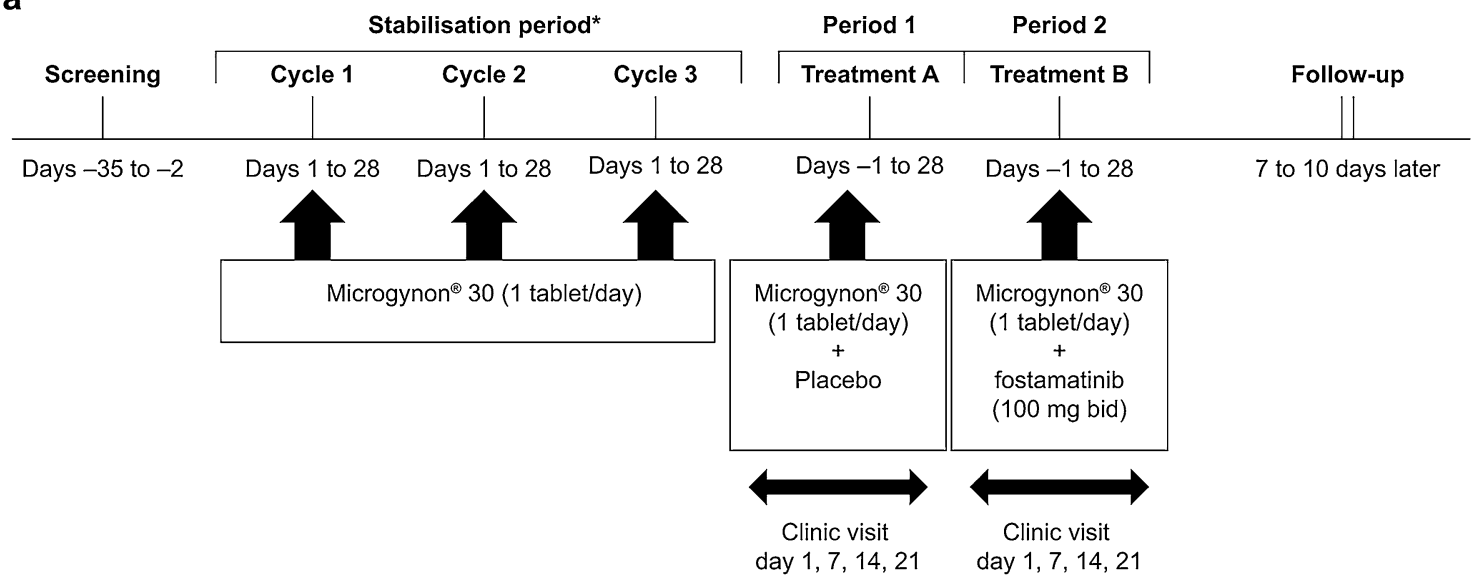

b

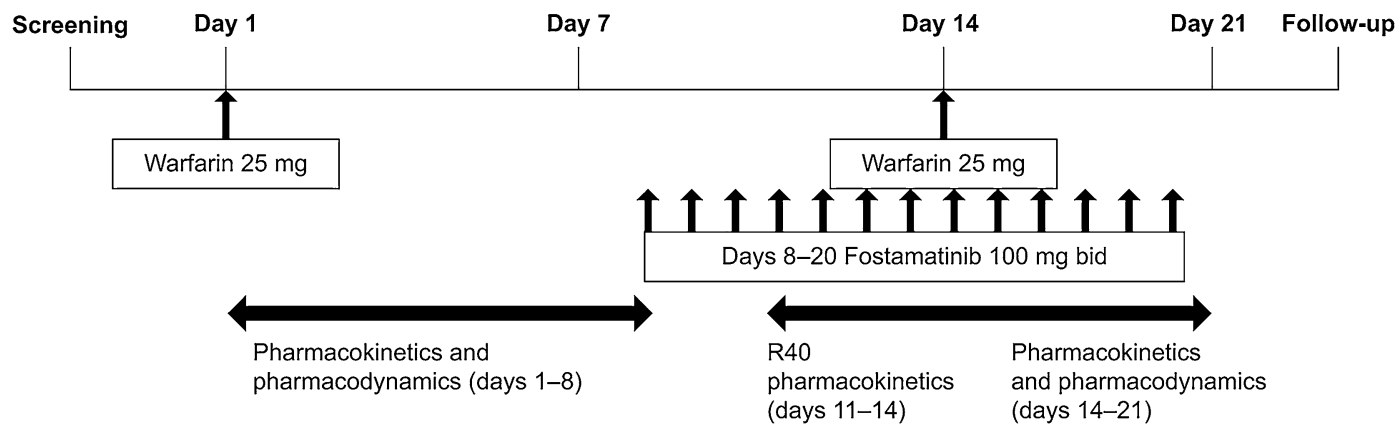

C

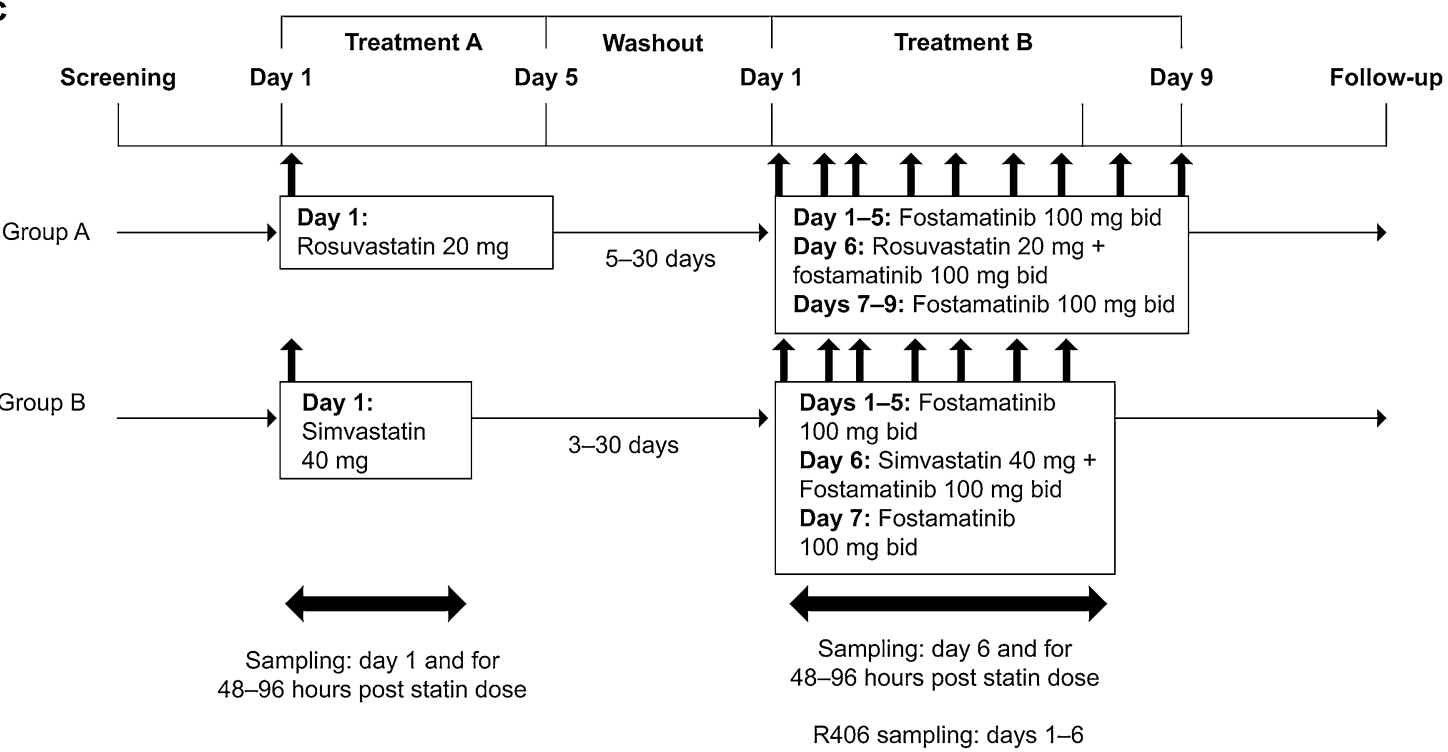

Fig. 1 Study designs for a OC interaction study, b warfarin interaction study, and $\mathbf{c}$ statin interaction study. Asterisks Stabilization period: those already taking Microgynon ${ }^{\circledR} 30$ continued taking it for at least 21 days from screening to day -1 of period 1 . Those not already taking Microgynon ${ }^{\circledR} 30$ started it after screening and continued for three stabilization cycles of at least 21 days. The last stabilization cycle could be extended up to a maximum of 49 days, for the purpose of synchronizing the cycles of healthy subjects so that they would participate in the study in groups. Bid twice daily, $O C$ oral contraceptive 
The $R$ - and $S$-warfarin method was used to analyze human plasma with sodium EDTA or lithium heparin anticoagulant. Samples were extracted by liquid-liquid extraction. After evaporation, the residue was reconstituted and analyzed. The standard curve range was 5-1500 ng/ $\mathrm{mL}$ for $R$ - and $S$-warfarin, using a plasma sample volume of $0.25 \mathrm{~mL}$. The LC used an Alltech Phenomenex Astec $\beta$ cyclodextrin Cyclobond I column with an isocratic mobile phase system [acetonitrile:acetic acid:TEA (1000:3:2.5, v:v:v)]. Detection was by a Sciex API 3000 or 4000 (negative ion APCI), with the transition monitored $307.1 \rightarrow 161.0$ for $R$ - and $S$-warfarin.

The simvastatin and simvastatin acid method was used to analyze human plasma with sodium heparin or K2EDTA anticoagulant. Samples were extracted by liquid-liquid extraction. After evaporation under nitrogen, the residue was reconstituted and analyzed. The standard curve range was from 0.05 to $50 \mathrm{ng} / \mathrm{mL}$ for simvastatin and 0.05 to $10 \mathrm{ng} / \mathrm{mL}$ for simvastatin acid, using a sample volume of $0.250 \mathrm{~mL}$. The LC used a Grace GenesisLightn C18 column with an isocratic mobile phase system [ $25 \%$ mobile phase A: (acetic acid $500 \mathrm{mM}, \mathrm{pH} 4.0$ ): water (10:90); $75 \%$ mobile phase $\mathrm{B}$ : acetonitrile] at a flow rate of $0.6 \mathrm{~mL} / \mathrm{min}$. Detection was by a Sciex API 5000, with the transition monitored $419 \rightarrow 199$ (positive ion electrospray ionization) for simvastatin and $435 \rightarrow 319$ (negative ion electrospray ionization) for simvastatin acid.

The Rosuvastatin method was used to analyze buffered human plasma treated with lithium heparin anticoagulant. Samples were extracted by supported liquid extraction (SLE). After evaporation, the residue was reconstituted and analyzed. The standard curve range was from 0.02 to $20 \mathrm{ng} / \mathrm{mL}$ for rosuvastatin, using a human plasma sample volume of $0.1 \mathrm{~mL}$. The LC used a Thermo Electron Corporation, Aquasil $\mathrm{C} 18$ column with a gradient mobile phase system [mobile phase A: water: formic acid (100:0.1); mobile phase B: acetonitrile: formic acid (100:0.1)]. Detection was by a Sciex API 5500 (positive ion electrospray ionization), with the transition monitored $482.2 \rightarrow 258.2$ for rosuvastatin.

R406 was extracted from EDTA plasma using liquidliquid extraction with MTBE. The extracts were subsequently dried under Nitrogen, reconstituted and analysed by LC-MS/MS. The LC method used a $0.1 \%$ formic acid water/acetonitrile gradient with a Chromolith SpeedROD RP-18e analytical column. The mass spectrometer (Sciex API 4000) used positive ion electrospray, monitoring the transition 471/451 (the equivalent was monitored for the deuterated internal standard). The analytical range was $2.50 \mathrm{ng} / \mathrm{mL}$ (LLOQ) to $2500 \mathrm{ng} / \mathrm{mL}$. In the OC study, LH, FSH and SHBG were analyzed using standard ELISA methods at Quintiles Drug Research Unit at Guy's Hospital.

\subsubsection{Pharmacokinetic Analyses}

Pharmacokinetic parameters were determined by noncompartmental analysis using WinNonlin ${ }^{\circledR}$ version 5.2 (Pharsight Corp, Mountain View, CA, USA), with SAS ${ }^{\circledR}$ version 9.2 (SAS Institute Inc, Cary, NC, USA) and SigmaPlot ${ }^{\circledR}$ version 9.0 (Systat Software Inc, San Jose, CA, USA) also used in statistical analysis.

In the OC study, pharmacokinetic parameters calculated for ethinyl estradiol and levonorgestrel included area under the concentration-time curve from zero to tau at steady state $\left(\mathrm{AUC}_{\mathrm{ss}}\right)$ and the maximum plasma concentration at steady state $\left(C_{\mathrm{max}, \mathrm{ss}}\right)$. The pharmacodynamic parameters calculated for progesterone, LH, FSH, and SHBG were $\mathrm{AUC}_{\mathrm{ss}}, C_{\mathrm{max}, \mathrm{ss}}$, the minimum plasma concentration at steady state, and the time to $C_{\mathrm{max}, \mathrm{ss}}\left(t_{\mathrm{max}, \mathrm{ss}}\right)$. Primary variables in the warfarin study were AUC and $C_{\max }$ for $R$ and $S$-warfarin. Pharmacodynamic measurements for this study were the maximum INR ( $\left.\operatorname{INR}_{\max }\right)$ and the area under the INR-time curve from zero to $168 \mathrm{~h}$ after dose $\left(\mathrm{AUC}_{\mathrm{INR}, 0-168}\right)$. In the statin study, the primary parameters were AUC and $C_{\max }$ for rosuvastatin and AUC from zero to the time of the last measurable concentration $\left(\mathrm{AUC}_{t}\right)$ and $C_{\max }$ for simvastatin acid. Pharmacokinetic parameters calculated for $\mathrm{R} 406$ were $\mathrm{AUC}_{\mathrm{ss}}, C_{\mathrm{max}, \mathrm{ss}}$, and $t_{\mathrm{max}, \mathrm{ss}}$ in the OC and warfarin studies, and AUC during a dosage interval $(\tau)\left(\mathrm{AUC}_{\tau}\right), C_{\max }$, and $t_{\max }$ in the statin study.

\subsubsection{Statistical Analyses}

In all three studies, all subjects who received at least one dose of investigational product were included in the safety analysis set. All available data were included in the safety analyses. The pharmacokinetic analysis set included only subjects who received one or more doses of investigational treatment and had one or more post-dose pharmacokinetic measurements without important protocol deviations. No adjustment or imputation was used for missing values, and analyses were not restricted to subjects with complete data.

A sample size of 28 subjects was estimated to provide $90 \%$ power that a two-sided $90 \%$ confidence interval (CI) for the ratios of interest $\left(C_{\mathrm{max}, \mathrm{ss}}\right.$ and $\mathrm{AUC}_{\mathrm{ss}}$ for each analyte) of OC administered with fostamatinib to that of OC alone would be completely contained within the pre-specified equivalence range of $0.80-1.25$, if there is truly no drug-drug interaction between OC and fostamatinib, based on a two-sided $5 \%$ significance test.

The intra-subject $\% \mathrm{CV}$ of ethinyl estradiol was assumed at $25 \%$. The intra-subject $\% \mathrm{CV}$ for levonorgestrel was assumed to be equal to or less than $25 \%$.

The warfarin study was not statistically powered in terms of claiming no effect of fostamatinib on exposure to 
$R$ - or $S$-warfarin (i.e., if the $90 \% \mathrm{CI}$ is within $0.80-1.25$ ). Interpretation of the results is based on the size of the treatment ratio and associated $90 \%$ CIs. To illustrate the size of effect that could be detected, it was estimated that 12 subjects would provide approximately $84 \%$ power to detect a $50 \%$ increase in AUC and $C_{\max }$, significant at the $5 \%$ level. This was based on data from various warfarin studies that suggested an approximate co-efficient of variation of $45 \%$ for both AUC and $C_{\max }$. A warfarin coefficient of variation of $45 \%$ was assumed for both AUC and $C_{\max }$.

In the statin study, pharmacokinetic parameters were analyzed using an analysis of variance model with fixed effects for treatment and subject, following a natural logarithmic transformation. Although the primary pharmacokinetic variables for rosuvastatin and simvastatin were AUC and $C_{\max }$, there were insufficient data to calculate AUC for simvastatin acid without extensive extrapolation. Therefore, $\mathrm{AUC}_{\mathrm{t}}$ was considered the primary pharmacokinetic variable in place of AUC for simvastatin acid only. This study was not statistically powered in terms of claiming no effect of fostamatinib on exposure to rosuvastatin or simvastatin. Interpretation of the results was based on the size of the treatment ratio and associated $90 \%$ CI. To illustrate the size of effect that could be detected, it was estimated that 18 completed subjects would provide approximately $80 \%$ power to detect a ratio of 1.27 or more in AUC and $C_{\max }$, using a two-sided $5 \%$ significance test. Intra-subject CVs of 21 and $27 \%$ for AUC and 34 and $38 \%$ for $C_{\max }$ were assumed for rosuvastatin and simvastatin, respectively. It was pre-planned to use least square mean data to summarise treatment exposure and to compare exposure across treatments for all studies. This was to accommodate the possibility that dropouts could occur for one treatment leaving an imbalance in numbers. In practice, there were no dropouts nor imbalance for some analyses but the least mean square approach was carried through so that it was not necessary to change the planned analysis once the data were available. Since there was a balance in $n$ in some analyses the use of least squares means will not have impacted on the results obtained because mean and least squares mean give the same result in this situation.

\subsubsection{Safety Assessments}

Safety and tolerability assessments included the incidence and severity of adverse events (AEs), clinical laboratory data, vital signs, 12-lead electrocardiograms, and physical examinations. AEs were tabulated and summarized according to the Medical Dictionary for Regulatory Activities.

\section{Results}

\subsection{Subject Demographics}

Subject demographics and baseline characteristics for all studies are shown in Table 1.

\subsection{Pharmacokinetics}

All assays for R406, ethinyl estradiol, levonorgestrel, $R$ and $S$-warfarin, rosuvastatin, simvastatin, and simvastatin acid performed reliably during the analyses.

In the OC study for the R406 analysis, precision (\%CV) and accuracy ( $\%$ bias) for the QC samples at three concentrations were $\leq 10.1 \%$ and within -4.0 to $-0.8 \%$, respectively. For the ethinyl estradiol analysis, precision and accuracy for the QC samples at three concentrations were $\leq 6.3 \%$ and within -3.4 to $5.2 \%$, respectively. For the levonorgestrel analysis, precision and accuracy for the QC samples at three concentrations were $\leq 5.3 \%$ and within -2.8 to $7.2 \%$, respectively.

For the warfarin study for the R406 analysis, precision and accuracy for the QC samples at three concentrations were $\leq 7.6 \%$ and within -4.0 to $-0.9 \%$, respectively. For the warfarin analysis, precision for the QC samples at three concentrations was $\leq 5.3 \%$ for $R$-warfarin and $\leq 5.5 \%$ for $S$-warfarin. Accuracy for the QC samples at three

Table 1 Baseline demographics and subject characteristics

\begin{tabular}{|c|c|c|c|c|}
\hline Characteristic & $\begin{array}{l}\text { OC } \\
\text { study } \\
(N=33)\end{array}$ & $\begin{array}{l}\text { Warfarin } \\
\text { study } \\
(N=15)\end{array}$ & $\begin{array}{l}\text { Rosuvastatin } \\
\text { (group A) } \\
n=21\end{array}$ & $\begin{array}{l}\text { Simvastatin } \\
\text { (group B) } \\
n=21\end{array}$ \\
\hline \multicolumn{5}{|l|}{ Sex } \\
\hline Men, $n(\%)$ & 0 & $14(93.3)$ & $20(95.2)$ & $21(100)$ \\
\hline $\begin{array}{l}\text { Women, } \\
n(\%)\end{array}$ & 33 (100) & $1(6.7)$ & $1(4.8)$ & 0 \\
\hline Age, years & 26 & 37 & $33(10)$ & $33(11)$ \\
\hline \multicolumn{5}{|l|}{ Race } \\
\hline White & $27(81.8)$ & $10(66.7)$ & $13(61.9)$ & $14(66.7)$ \\
\hline Black & $4(12.1)$ & $5(33.3)$ & $8(38.1)$ & $5(23.8)$ \\
\hline $\begin{array}{l}\text { American } \\
\text { Indian/ } \\
\text { Alaskan }\end{array}$ & 0 & 0 & 0 & $1(4.8)$ \\
\hline Asian & $2(6.1)$ & 0 & 0 & $1(4.8)$ \\
\hline $\begin{array}{r}\text { Weight }(\mathrm{kg}) \\
\text { mean }(\mathrm{SD})\end{array}$ & $\begin{array}{l}63.8 \\
(9.4)\end{array}$ & $87.2(8.0)$ & $83.7(10.8)$ & $80.8(9.9)$ \\
\hline $\begin{array}{l}\text { Body mass } \\
\text { index }(\mathrm{kg} / \\
\left.\mathrm{m}^{2}\right) \text {, mean } \\
(\mathrm{SD})\end{array}$ & $\begin{array}{l}23.7 \\
(3.0)\end{array}$ & $27.4(3.5)$ & $26.2(2.8)$ & $25.6(2.7)$ \\
\hline
\end{tabular}

$O C$ oral contraceptive, $S D$ standard deviation 
Table 2 Statistical comparison of primary oral contraceptive pharmacokinetic and pharmacodynamic endpoints following co-administration of Microgynon $^{\circledR} 30$ (1 tablet/day comprising $30 \mu \mathrm{g}$ ethinyl estradiol and $150 \mu \mathrm{g}$ levonorgestrel) and fostamatinib (100 mg twice daily)

\begin{tabular}{|c|c|c|c|c|c|c|}
\hline \multirow[t]{2}{*}{ Analyte } & \multirow[t]{2}{*}{ Parameter (units) } & \multirow[t]{2}{*}{ Treatment } & \multirow[t]{2}{*}{$n$} & \multirow[t]{2}{*}{ Geometric LS mean } & \multicolumn{2}{|c|}{$\begin{array}{l}\text { Microgynon }+ \text { fostamatinib/ } \\
\text { microgynon alone }\end{array}$} \\
\hline & & & & & Ratio (\%) & $90 \% \mathrm{CI}$ \\
\hline \multirow[t]{4}{*}{ Ethinyl estradiol } & \multirow[t]{2}{*}{$\mathrm{AUC}_{\mathrm{ss}}(\mathrm{ng} \cdot \mathrm{h} / \mathrm{mL})$} & Microgynon alone & 27 & 828.1 & & \\
\hline & & Microgynon + fostamatinib & 27 & 1062 & 128.2 & $121.1-135.8$ \\
\hline & \multirow[t]{2}{*}{$C_{\max , \mathrm{ss}}(\mathrm{ng} / \mathrm{mL})$} & Microgynon alone & 27 & 86.2 & & \\
\hline & & Microgynon + fostamatinib & 27 & 115.7 & 134.3 & $126.1-143.0$ \\
\hline \multirow[t]{4}{*}{ Levonorgestrel } & \multirow[t]{2}{*}{$\mathrm{AUC}_{\mathrm{ss}}(\mathrm{ng} \cdot \mathrm{h} / \mathrm{mL})$} & Microgynon alone & 27 & 75,970 & & \\
\hline & & Microgynon + fostamatinib & 27 & 79,830 & 105.1 & $97.5-113.2$ \\
\hline & \multirow[t]{2}{*}{$C_{\max , \mathrm{ss}}(\mathrm{ng} / \mathrm{mL})$} & Microgynon alone & 27 & 6652 & & \\
\hline & & Microgynon + fostamatinib & 27 & 6439 & 96.8 & $90.4-103.6$ \\
\hline \multirow[t]{4}{*}{ Progesterone } & \multirow[t]{2}{*}{$\mathrm{AUC}_{\mathrm{ss}}(\mathrm{nmol} \cdot \mathrm{h} / \mathrm{L})$} & Microgynon alone & 27 & 66.5 & & \\
\hline & & Microgynon + fostamatinib & 27 & 69.4 & 104.3 & $96.4-112.9$ \\
\hline & \multirow[t]{2}{*}{$C_{\max , \mathrm{ss}}(\mathrm{nmol} / \mathrm{L})$} & Microgynon alone & 27 & 4.9 & & \\
\hline & & Microgynon + fostamatinib & 27 & 4.9 & 99.8 & $90.4-110.1$ \\
\hline \multirow[t]{4}{*}{ Sex hormone-binding globulin } & \multirow[t]{2}{*}{$\mathrm{AUC}_{\mathrm{ss}}(\mathrm{nmol} \cdot \mathrm{h} / \mathrm{L})$} & Microgynon alone & 27 & 2020 & & \\
\hline & & Microgynon + fostamatinib & 27 & 2023 & 100.1 & $94.9-105.7$ \\
\hline & \multirow[t]{2}{*}{$C_{\max , \mathrm{ss}}(\mathrm{nmol} / \mathrm{L})$} & Microgynon alone & 27 & 92.6 & & \\
\hline & & Microgynon + fostamatinib & 27 & 92.9 & 100.4 & $94.3-106.9$ \\
\hline \multirow[t]{4}{*}{ Follicle-stimulating hormone } & \multirow[t]{2}{*}{$\mathrm{AUC}_{\mathrm{ss}}(\mathrm{IU} \cdot \mathrm{h} / \mathrm{L})$} & Microgynon alone & 27 & 5.6 & & \\
\hline & & Microgynon + fostamatinib & 27 & 4.3 & 75.6 & $62.1-92.1$ \\
\hline & \multirow[t]{2}{*}{$C_{\max , \mathrm{ss}}(\mathrm{IU} / \mathrm{L})$} & Microgynon alone & 27 & 0.3 & & \\
\hline & & Microgynon + fostamatinib & 27 & 0.2 & 76.0 & $56.2-102.7$ \\
\hline \multirow[t]{4}{*}{ Luteinizing hormone } & \multirow[t]{2}{*}{$\mathrm{AUC}_{\mathrm{ss}}(\mathrm{IU} \cdot \mathrm{h} / \mathrm{L})$} & Microgynon alone & 27 & 4.4 & & \\
\hline & & Microgynon + fostamatinib & 27 & 3.7 & 83.2 & $65.5-105.7$ \\
\hline & \multirow[t]{2}{*}{$C_{\max , \mathrm{ss}}(\mathrm{IU} / \mathrm{L})$} & Microgynon alone & 27 & 0.3 & & \\
\hline & & Microgynon + fostamatinib & 27 & 0.2 & 75.6 & $51.3-111.6$ \\
\hline
\end{tabular}

Results were analyzed by employing a linear fixed-effects model with treatment and subject as fixed effects

$A U C_{s s}$ area under the plasma concentration-time curve during the dosing interval at steady state, $C I$ confidence interval, $C_{m a x, s s}$ maximum plasma concentration at steady state, $L S$ least-squares

concentrations was within -10.0 to $-4.7 \%$ for $R$-warfarin and within -10.0 to $-4.0 \%$ for $S$-warfarin.

For the statin study for the R406 analysis, precision and accuracy for the QC samples at three concentrations were $\leq 5.1 \%$ and within $6.8-9.5 \%$, respectively. For the simvastatin analysis, precision for the QC samples at three concentrations was $\leq 7.2 \%$ for simvastatin and $\leq 5.8 \%$ for simvastatin acid. Accuracy for the QC samples at three concentrations was within -9.1 to $2.0 \%$ for simvastatin and within 3.3-12.0\% for simvastatin acid. For the rosuvastatin analysis, precision and accuracy for the QC samples at three concentrations were $\leq 5.4 \%$ and within -0.0 to $2.7 \%$, respectively.

\subsubsection{OC Interaction Study}

Thirty-three subjects were recruited and six discontinued treatment.
Levonorgestrel concentrations were similar throughout the dosing interval when $\mathrm{OC}$ was co-administered with fostamatinib and when it was administered alone. The least-squares (LS) geometric means for levonorgestrel $\mathrm{AUC}_{\mathrm{ss}}$ and $C_{\text {max,ss }}$ were similar across treatments (Table 2; Fig. 2), with treatment ratios of $105.1 \%(90 \% \mathrm{CI}$ 97.5-113.2) and 96.8\% (90.4-103.6), respectively. Individual $\mathrm{AUC}_{\mathrm{ss}}$ and $C_{\mathrm{max}, \mathrm{ss}}$ ratios (OC plus fostamatinib/OC alone) ranged from 71.1 to $182 \%$ and from 65.4 to $175 \%$, respectively.

Ethinyl estradiol $\mathrm{AUC}_{\mathrm{ss}}$ and $C_{\text {max,ss }}$ increased when OC was co-administered with fostamatinib, with geometric LS mean treatment ratios of $128.2 \%$ (90\% CI 121.1-135.8) and $134.3 \% \quad(90 \%$ CI 126.1-143.0), respectively (Table 2; Fig. 2). These trends were also observed on an individual basis, with individual $\mathrm{AUC}_{\mathrm{ss}}$ and $C_{\max , \mathrm{ss}}$ ratios ranging from 87.8 to $179 \%$ and from 95.3 to $231 \%$, respectively. 

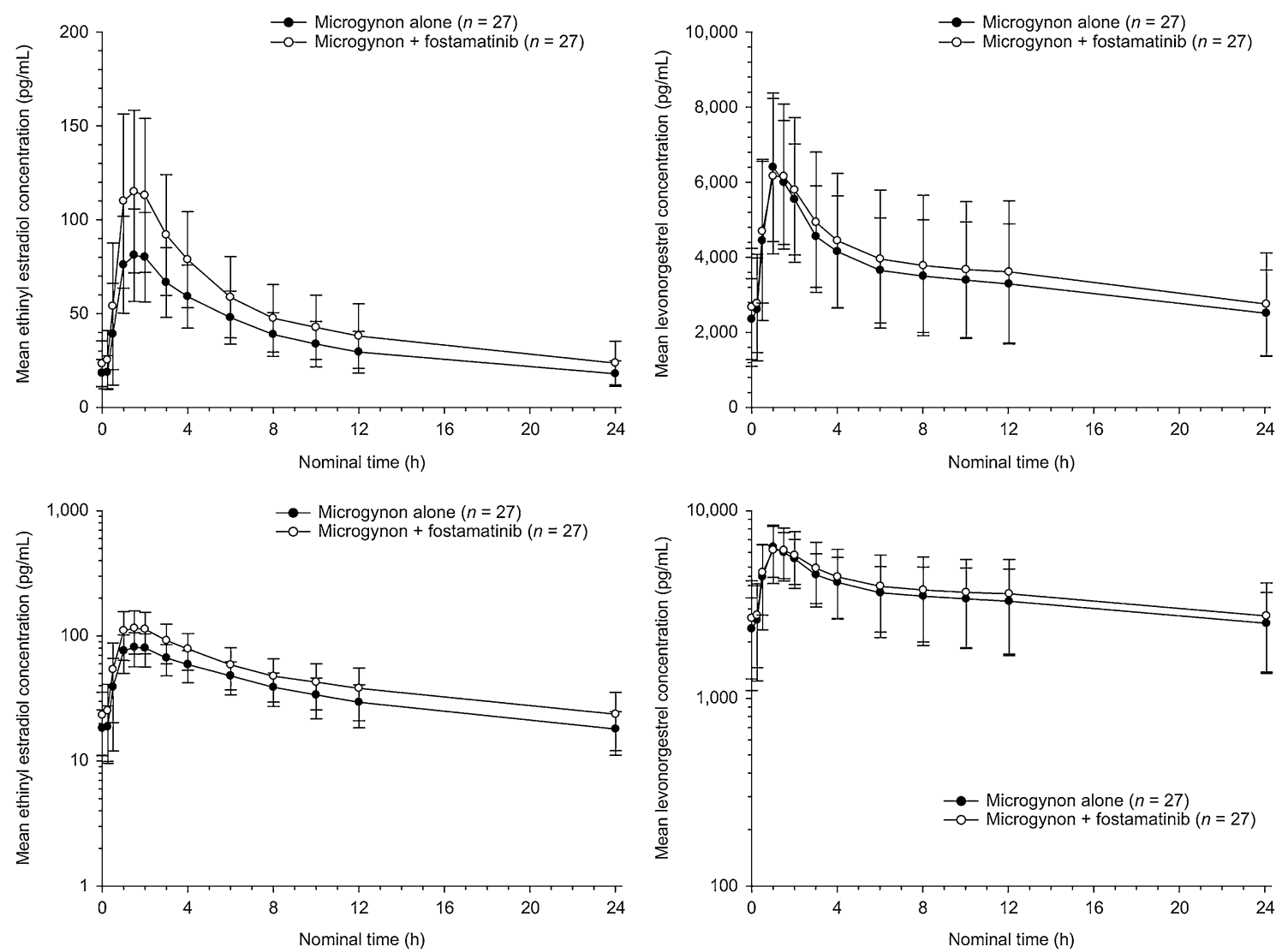

Fig. 2 Mean plasma concentrations of ethinyl estradiol and levonorgestrel, with and without fostamatinib co-administration

Table 3 Statistical comparison of primary $R$ - and $S$-warfarin pharmacokinetic and pharmacodynamic parameters following co-administration of warfarin $25 \mathrm{mg}$ and fostamatinib (100 $\mathrm{mg}$ twice daily)

\begin{tabular}{|c|c|c|c|c|c|c|}
\hline \multirow[t]{2}{*}{ Analyte } & \multirow[t]{2}{*}{ Parameter (units) } & \multirow[t]{2}{*}{ Treatment } & \multirow[t]{2}{*}{$n$} & \multirow[t]{2}{*}{ Geometric LS mean } & \multicolumn{2}{|c|}{ Warfarin + fostamatinib/warfarin alone } \\
\hline & & & & & Ratio (\%) & $90 \% \mathrm{CI}$ \\
\hline \multirow[t]{4}{*}{$R$-Warfarin } & \multirow[t]{2}{*}{ AUC (ng.h/mL) } & Warfarin alone & 11 & 65,228 & & \\
\hline & & Warfarin + fostamatinib & 11 & 76,828 & 117.8 & $113.0-122.7$ \\
\hline & \multirow[t]{2}{*}{$C_{\max }(\mathrm{ng} / \mathrm{mL})$} & Warfarin alone & 13 & 1177 & & \\
\hline & & Warfarin + fostamatinib & 13 & 1202 & 102.1 & $97.0-107.5$ \\
\hline \multirow[t]{4}{*}{$S$-Warfarin } & \multirow[t]{2}{*}{$\operatorname{AUC}(\mathrm{ng} \cdot \mathrm{h} / \mathrm{mL})$} & Warfarin alone & 14 & 43,014 & & \\
\hline & & Warfarin + fostamatinib & 14 & 48,528 & 112.8 & $107.4-118.5$ \\
\hline & \multirow[t]{2}{*}{$C_{\max }(\mathrm{ng} / \mathrm{mL})$} & Warfarin alone & 14 & 1188 & & \\
\hline & & Warfarin + fostamatinib & 14 & 1173 & 98.7 & $91.5-106.4$ \\
\hline \multirow[t]{4}{*}{ INR } & \multirow[t]{2}{*}{$\mathrm{INR}_{\max }$} & Warfarin alone & 14 & 1.65 & & \\
\hline & & Warfarin + fostamatinib & 14 & 1.48 & 89.7 & $84.6-95.2$ \\
\hline & \multirow[t]{2}{*}{$\mathrm{AUC}_{\mathrm{INR}, 0-168}(\mathrm{~h})$} & Warfarin alone & 14 & 206.65 & & \\
\hline & & Warfarin + fostamatinib & 14 & 200.44 & 97.0 & $95.3-98.8$ \\
\hline
\end{tabular}

Results based on analysis of variance model on log-transformed pharmacokinetic parameters with fixed effects for treatment and subject $A U C$ area under the plasma concentration-time curve extrapolated to infinity, $A U C_{I N R, 0-168}$ area under the INR time curve from zero to $168 \mathrm{~h}$

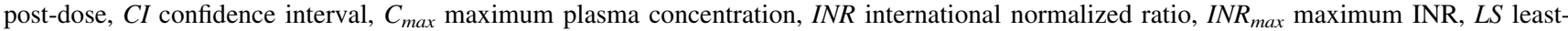
squares 

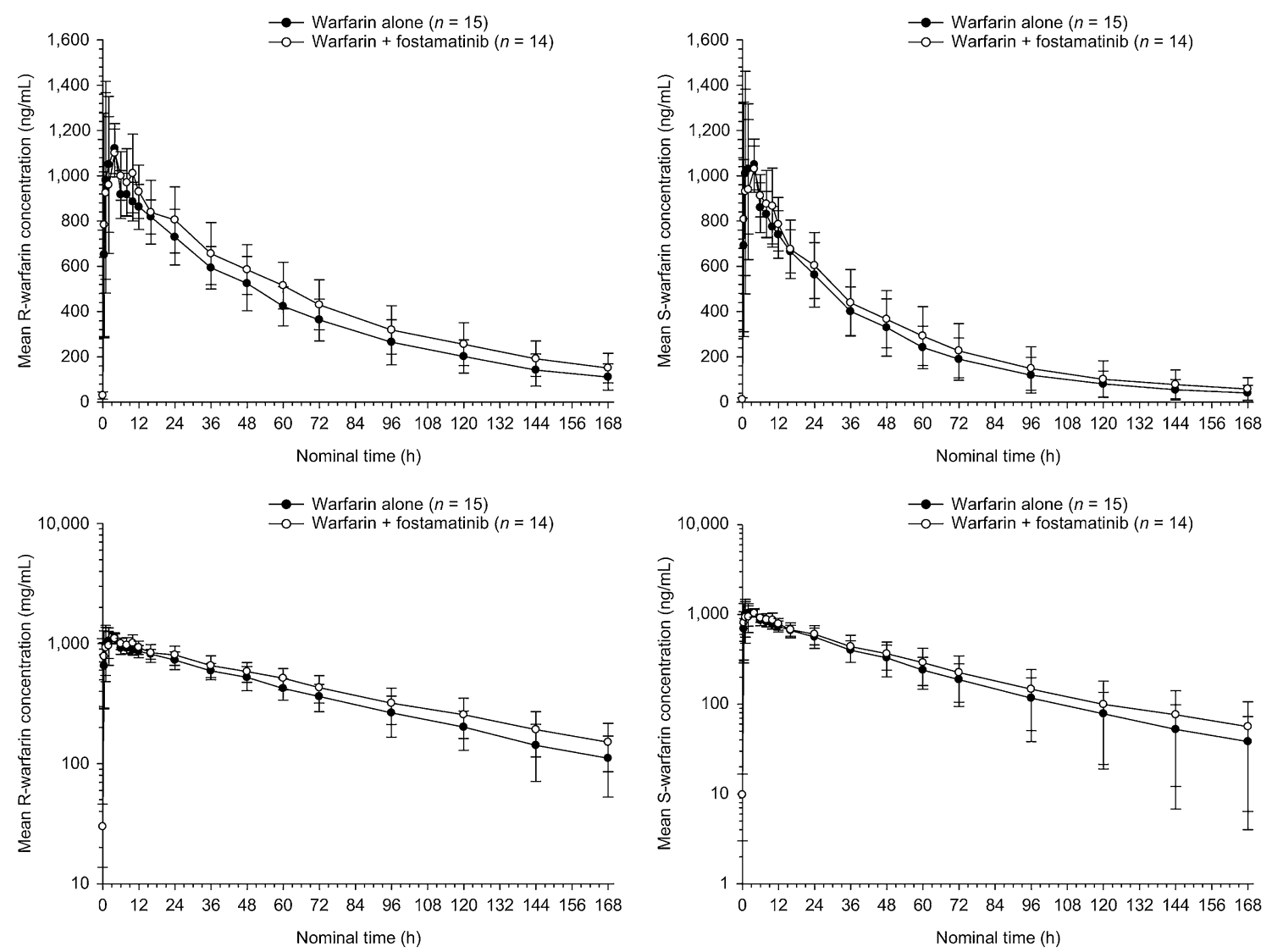

Fig. 3 Mean plasma concentrations of $R$ - and $S$-warfarin, with and without fostamatinib co-administration

\subsubsection{Warfarin Interaction Study}

Table 3 compares $R$ - and $S$-warfarin AUC and $C_{\max }$ when warfarin was administered alone and in combination with fostamatinib.

In the warfarin study, 15 subjects were enrolled. One subject was prematurely withdrawn from the study on day 8. Subject E0001009 received only one warfarin administration on day 1 and no fostamatinib administrations. The following subjects were excluded from the pharmacokinetic analysis set: subject E0001009: no data available; subject E0001010: pre-dose plasma concentration equaled $5.4 \%$ of $C_{\max }$; subject E0001014: AUC not reported due to high \%AUC extrapolated; and subject E0001023: AUC not reported due to high \%AUC extrapolated.

Concomitant administration of fostamatinib with warfarin slightly increased the $R$ - and $S$-warfarin AUC values compared with when warfarin was given alone [treatment difference $117.8 \%$ (90\% CI 113.0-122.7) and $112.8 \%$ (90\% CI 107.4-118.5), respectively]. This was consistent across the majority of subjects, with AUC differences ranging from 5.0 to $33.0 \%$ for $R$-warfarin and 0.0 to $36.0 \%$ for $S$-warfarin.
Geometric LS mean $C_{\max }$ of $R$ - and $S$-warfarin was unaffected when warfarin was co-administered with fostamatinib, with treatment differences of $102.1 \%$ (90\% CI 97.0-107.5) and $98.7 \%$ (90\% CI 91.5-106.4), respectively. On an individual basis, $C_{\max }$ differences (warfarin alone to warfarin plus fostamatinib) ranged from -16.1 to $22 \%$ for $R$-warfarin and from -25.6 to $27 \%$ for $S$-warfarin. Trailing mean plasma concentrations were slightly higher for each analyte for the combined treatment (Fig. 3). Furthermore, warfarin co-administration with fostamatinib resulted in an increase in the geometric mean terminal halflife $\left(t_{1 / 2 \lambda \mathrm{z}}\right)$ from 50.7 to $57.3^{\prime} \mathrm{h}$ for $R$-warfarin and from 34.5 to 40.6 'h for $S$-warfarin.

\subsubsection{Statin Interaction Study}

A total of 42 subjects participated in the study; there were 21 subjects in each group. All 21 subjects in group A (rosuvastatin) completed the study per protocol. In group B (simvastatin), 19 volunteers completed the study and two volunteers were withdrawn.

When rosuvastatin $20 \mathrm{mg}$ was co-administered with fostamatinib, an increase in AUC [treatment difference 
Table 4 Statistical comparison of key rosuvastatin, simvastatin, and simvastatin acid parameters following co-administration of rosuvastatin (20 mg) or simvastatin (40 mg) with fostamatinib (100 mg twice daily)

\begin{tabular}{|c|c|c|c|c|c|c|}
\hline \multirow[t]{2}{*}{ Analyte } & \multirow[t]{2}{*}{ Parameter (units) } & \multirow[t]{2}{*}{ Treatment } & \multirow[t]{2}{*}{$n$} & \multirow[t]{2}{*}{ Geometric LS mean } & \multicolumn{2}{|c|}{ Statin + fostamatinib/statin alone } \\
\hline & & & & & Ratio (\%) & $90 \% \mathrm{CI}$ \\
\hline \multirow[t]{6}{*}{ Rosuvastatin } & \multirow[t]{2}{*}{ AUC (ng.h/mL) } & Rosuvastatin alone & 21 & 93.7 & & \\
\hline & & Rosuvastatin + fostamatinib & 21 & 183.4 & 195.6 & $177.6-215.3$ \\
\hline & \multirow[t]{2}{*}{$\mathrm{AUC}_{t}(\mathrm{ng} \cdot \mathrm{h} / \mathrm{mL})$} & Rosuvastatin alone & 21 & 92.2 & & \\
\hline & & Rosuvastatin + fostamatinib & 21 & 181.6 & 197.1 & $178.84-217.3$ \\
\hline & \multirow[t]{2}{*}{$C_{\max }(\mathrm{ng} / \mathrm{mL})$} & Rosuvastatin alone & 21 & 10.6 & & \\
\hline & & Rosuvastatin + fostamatinib & 21 & 19.9 & 188.4 & $169.4-209.6$ \\
\hline \multirow[t]{6}{*}{ Simvastatin } & \multirow[t]{2}{*}{ AUC (ng.h/mL) } & Simvastatin alone & 21 & 27.5 & & \\
\hline & & Simvastatin + fostamatinib & 19 & 45.1 & 164.1 & $133.1-202.4$ \\
\hline & \multirow[t]{2}{*}{$\mathrm{AUC}_{t}(\mathrm{ng} \cdot \mathrm{h} / \mathrm{mL})$} & Simvastatin alone & 21 & 26.1 & & \\
\hline & & Simvastatin + fostamatinib & 19 & 44.4 & 170.1 & $137.1-211.0$ \\
\hline & \multirow[t]{2}{*}{$C_{\max }(\mathrm{ng} / \mathrm{mL})$} & Simvastatin alone & 21 & 6.5 & & \\
\hline & & Simvastatin + fostamatinib & 19 & 13.9 & 212.5 & $164.7-274.3$ \\
\hline \multirow[t]{4}{*}{ Simvastatin acid } & \multirow[t]{2}{*}{$\mathrm{AUC}_{t}(\mathrm{ng} \cdot \mathrm{h} / \mathrm{mL})$} & Simvastatin alone & 21 & 12.6 & & \\
\hline & & Simvastatin + fostamatinib & 19 & 22.0 & 174.2 & $150.0-202.2$ \\
\hline & \multirow[t]{2}{*}{$C_{\max }(\mathrm{ng} / \mathrm{mL})$} & Simvastatin alone & 21 & 1.4 & & \\
\hline & & Simvastatin + fostamatinib & 19 & 2.6 & 182.8 & $156.7-213.3$ \\
\hline
\end{tabular}

Results based on linear model with fixed effects for treatment and subject

$A U C$ area under the plasma concentration-time curve from zero to infinity, $A U C_{t}$ AUC from zero to the time of the last measurable concentration, $C I$ confidence interval, $C_{\max }$, maximum plasma concentration, $L S$ least-squares

$195.6 \%\left(90 \%\right.$ CI 177.6-215.3)] and $\mathrm{AUC}_{t}[197.1 \%$ (90\% CI 178.8-217.3)] occurred (Table 4; Fig. 4a). An increase was also observed in $C_{\max }$ for rosuvastatin [188.4 \% (90\% CI 169.4-209.6)]. This increase in exposure was observed in all subjects, with parameter ratios for AUC and $C_{\max }$ ranging from 1.16 to $3.34 \%$.

Increases in simvastatin acid $\mathrm{AUC}_{\mathrm{t}}$ and $C_{\max }$ also occurred, with treatment differences of $174.2 \%(90 \% \mathrm{CI}$ 150.0-202.2) and $182.8 \% \quad(90 \%$ CI $156.7-213.3)$, respectively, when simvastatin was co-administered with fostamatinib (Table 4; Fig. 4b). This increase in exposure was observed in all subjects, with parameter ratios for $\mathrm{AUC}_{\mathrm{t}}$ and $C_{\max }$ ranging from 1.03 to $5.35 \%$. The half-life of simvastatin acid was reduced by about $1.5 \mathrm{~h}$ in the presence of fostamatinib.

For simvastatin (lactone) itself $(40 \mathrm{mg})$, co-administration with fostamatinib increased $\mathrm{AUC}$ and $\mathrm{AUC}_{t}$, with treatment differences of $164.1 \%$ (90\% CI 133.1-202.4) and $170.1 \% \quad(90 \%$ CI $137.1-211.0)$, respectively (Table 4). The presence of fostamatinib doubled the $C_{\max }$ of simvastatin [treatment difference $212.5 \%(90 \% \mathrm{CI}$ 164.7-274.3)], with a marginal change in $t_{\max }$. Simvastatin $t_{1 / 2 \lambda z}$ decreased by approximately $3 \mathrm{~h}$, which was accompanied by a net apparent reduction in clearance of $40.3 \%$. This increase in exposure was seen in most subjects, with parameter ratios for AUC and $C_{\max }$ ranging from 0.389 to $6.52 \%$.
There were no clear trends between BCRP and OATP1B1 genotype and exposure to rosuvastatin or simvastatin, measured by either AUC or AUC treatment ratio.

\subsubsection{R406 Exposure: All Studies}

Generally, R406 exposure was consistent with the administered fostamatinib dose in each study (Table 5). Over the 12-h dosing interval in the OC study (period 2, day 21), the R406 steady-state plasma geometric mean $C_{\text {max,ss }}$ and $\mathrm{AUC}_{\mathrm{ss}}$ were $812 \mathrm{ng} / \mathrm{mL}$ and $5020 \mathrm{ng} \cdot \mathrm{h} / \mathrm{mL}$, respectively. During the dosing period in the warfarin study, R406 had a geometric mean $C_{\text {max ss }}$ of $557 \mathrm{ng} / \mathrm{mL}$ and $\mathrm{AUC}_{\mathrm{ss}}$ of $4400 \mathrm{ng} \cdot \mathrm{h} / \mathrm{mL}$.

Only the statin study design allowed for a comparison of fostamatinib exposure with and without co-administration (Table 5). In group A, comparison of the mean R406 $\mathrm{AUC}_{\tau}$ and $C_{\max }$ when fostamatinib was administered alone with those for co-administration with rosuvastatin revealed slight increases, with treatment differences of $109.9 \%$ $(90 \%$ CI $104.4-115.7)$ and $112.9 \% \quad(90 \% \quad$ CI 102.2-124.8), respectively. Subjects in group B also demonstrated small changes in R406 exposure between treatment with fostamatinib alone and in combination with simvastatin. $\mathrm{AUC}_{\tau}$ and $C_{\max }$ had reported treatment differences of $110.7 \%$ (90\% CI 100.8-121.5) and $111.6 \%$ (90\% CI 98.0- 127.0), respectively, but individual values 

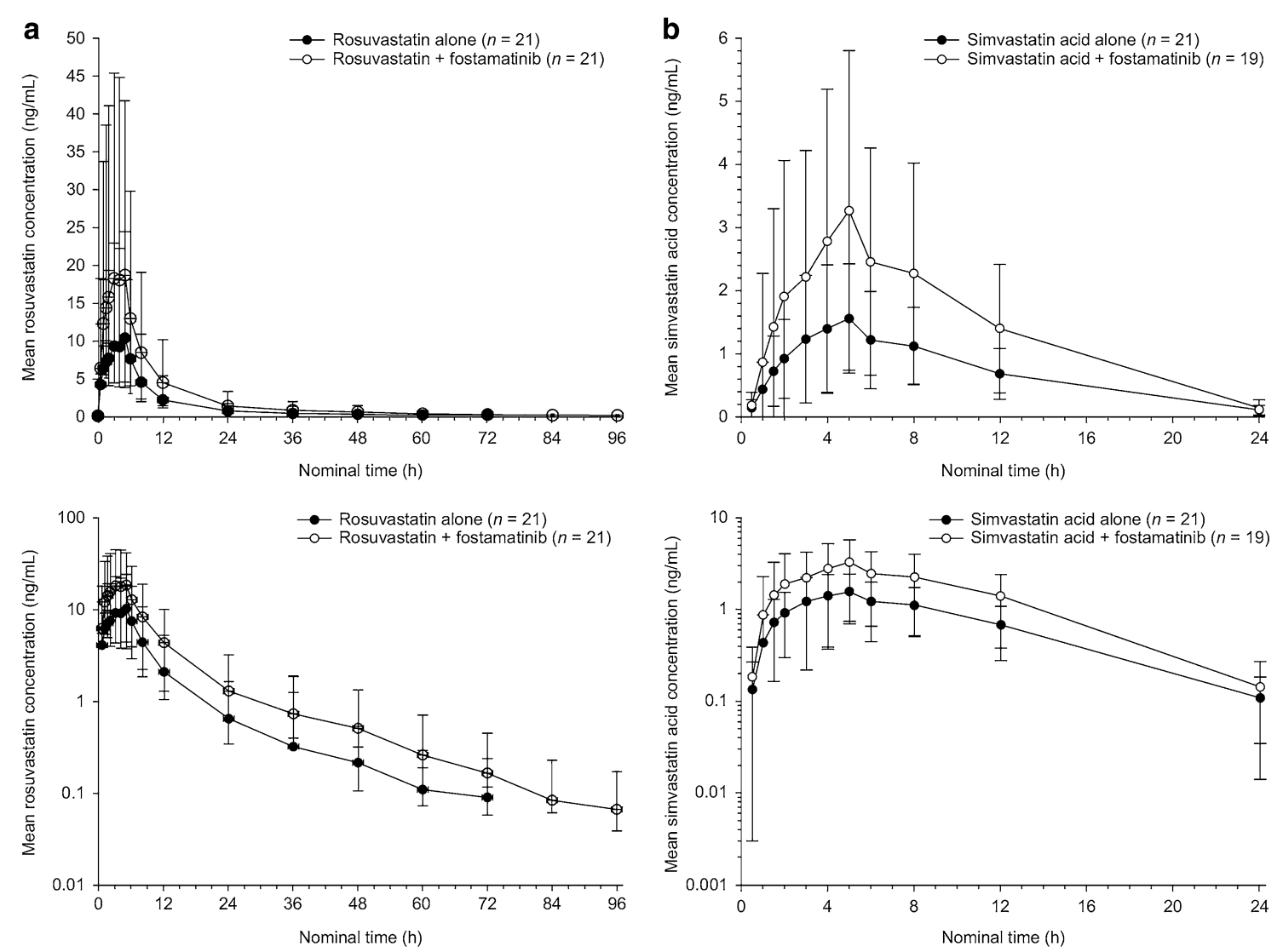

Fig. 4 a Mean plasma concentrations of rosuvastatin, with and without fostamatinib co-administration. b Mean plasma concentrations of simvastatin acid, with and without fostamatinib co-administration

did not show a clear pattern of increase or decrease for either parameter. The half-life of R406 is typically $\sim 14 \mathrm{~h}$, though it was not determined in the current studies.

\subsection{Pharmacodynamics}

\subsubsection{OC Interaction Study}

The main pharmacodynamic findings for the OC study are summarized in Table 2. Progesterone concentrations were similar across both treatments on day 21. Progesterone $\mathrm{AUC}_{\mathrm{ss}}$ and $C_{\mathrm{max}, \mathrm{ss}}$ were unaffected by fostamatinib, with geometric LS mean treatment differences of $104.3 \%$ (90\% CI 96.4-112.9) and 99.8\% (90\% CI 90.4-110.1), respectively. Similarly, SHBG concentrations were comparable across treatments, and $\mathrm{AUC}_{\mathrm{ss}}$ and $C_{\mathrm{max}, \mathrm{ss}}$ were unaffected by fostamatinib co-administration, with geometric LS mean treatment differences of $100.1 \%$ (90 \% CI 94.9-105.7) and $100.4 \% \quad(90 \%$ CI $94.3-106.9)$, respectively.

$\mathrm{AUC}_{\mathrm{ss}}$ and $C_{\mathrm{max}, \mathrm{ss}}$ for $\mathrm{LH}$ decreased following co-administration of fostamatinib with Microgynon ${ }^{\circledR} 30$, with geometric LS mean treatment differences of $83.2 \%$ (90\%
CI $\quad 65.5-105.7)$ and $75.6 \% \quad(90 \%$ CI $51.3-111.6)$, respectively. Fostamatinib co-administration also decreased FSH exposure, with geometric LS mean treatment differences in $\mathrm{AUC}_{\mathrm{ss}}$ and $C_{\max }$ of $75.6 \%(90 \% \mathrm{CI}$ $62.1-92.1)$ and $76.0 \%$ (90\% CI 56.2-102.7), respectively.

\subsubsection{Warfarin Interaction Study}

$\mathrm{AUC}_{\mathrm{INR}, 0-168}$ and $\mathrm{INR}_{\max }$ trended down during steadystate fostamatinib co-administration versus warfarin alone (Table 3), with geometric LS mean treatment differences of $97.0 \%$ (90\% CI 95.3-98.8) and $89.7 \%$ (90\% CI 84.6-95.2), respectively.

\subsection{Safety Assessments}

There were no deaths, serious AEs, or severe AEs. Furthermore, co-administration of fostamatinib alongside investigational medications produced no clinically relevant changes regarding laboratory measurements, vital signs, electrocardiogram, or physical examination. The most frequently reported AEs by preferred term for each treatment in each study are presented in Table 6 . 
Table 5 Key R406 pharmacokinetic parameters across OC, warfarin, and statin studies

\begin{tabular}{|c|c|c|c|c|c|c|}
\hline \multirow[t]{2}{*}{ Study } & \multirow{2}{*}{$\begin{array}{l}\text { Parameter } \\
\text { (units) }\end{array}$} & \multirow[t]{2}{*}{ Treatment } & \multirow[t]{2}{*}{$n$} & \multirow{2}{*}{$\begin{array}{l}\text { Geometric LS } \\
\text { mean }\end{array}$} & \multicolumn{2}{|c|}{ Pair-wise comparisons } \\
\hline & & & & & $\begin{array}{l}\text { Ratio } \\
(\%)\end{array}$ & $90 \% \mathrm{CI}$ \\
\hline \multirow[t]{2}{*}{ OC study ${ }^{\mathrm{a}}$} & $\begin{array}{l}\mathrm{AUC}_{\mathrm{ss}}(\mathrm{ng} \cdot \mathrm{h} / \\
\mathrm{mL})\end{array}$ & $\begin{array}{l}\text { Fostamatinib + oral } \\
\text { contraceptive }\end{array}$ & 27 & $5020^{\mathrm{b}}$ & - & - \\
\hline & $C_{\max , \mathrm{ss}}(\mathrm{ng} \cdot \mathrm{mL})$ & $\begin{array}{l}\text { Fostamatinib }+ \text { oral } \\
\text { contraceptive }\end{array}$ & 27 & $812^{\mathrm{b}}$ & - & - \\
\hline \multirow[t]{2}{*}{ Warfarin study ${ }^{\mathrm{a}}$} & $\begin{array}{l}\mathrm{AUC}_{\mathrm{ss}}(\mathrm{ng} \cdot \mathrm{h} / \\
\mathrm{mL})\end{array}$ & Fostamatinib + warfarin & 14 & $4400^{\mathrm{b}}$ & - & - \\
\hline & $C_{\text {max,ss }}($ ng.mL) & Fostamatinib + warfarin & 14 & $557^{\mathrm{b}}$ & - & - \\
\hline \multirow{4}{*}{$\begin{array}{l}\text { Statin study, group A } \\
\text { (rosuvastatin) }\end{array}$} & \multirow[t]{2}{*}{$\mathrm{AUC}_{\tau}(\mathrm{ng} \cdot \mathrm{h} / \mathrm{mL})$} & Fostamatinib alone & 21 & 5667 & & \\
\hline & & Fostamatinib + rosuvastatin & 21 & 6228 & 109.9 & $104.4-115.7$ \\
\hline & \multirow[t]{2}{*}{$C_{\max }(\mathrm{ng} / \mathrm{mL})$} & Fostamatinib alone & 21 & 790.0 & & \\
\hline & & Fostamatinib + rosuvastatin & 21 & 892.3 & 112.9 & $102.2-124.8$ \\
\hline \multirow[t]{4}{*}{ Statin study, group B (simvastatin) } & \multirow[t]{2}{*}{$\mathrm{AUC}_{\tau}(\mathrm{ng} \cdot \mathrm{h} / \mathrm{mL})$} & Fostamatinib alone & 19 & 6056 & & \\
\hline & & Fostamatinib + simvastatin & 19 & 6701 & 110.66 & $100.8-121.5$ \\
\hline & \multirow[t]{2}{*}{$C_{\max }(\mathrm{ng} / \mathrm{mL})$} & Fostamatinib alone & 19 & 876.1 & & \\
\hline & & Fostamatinib + simvastatin & 19 & 977.7 & 111.6 & $98.0-127.0$ \\
\hline
\end{tabular}

Results based on fixed-effects model with fixed effects for treatment and subject

$A U C_{s s}$ area under the plasma concentration-time curve during the dosing interval at steady state, $A U C_{\tau}$ AUC over the dosing interval, $C I$ confidence interval, $C_{\max }$, maximum plasma concentration, $C_{\max , s s}$ maximum plasma concentration at steady state, $L S$ least-squares, $O C$ oral contraceptive

a The OC and warfarin studies did not include fostamatinib-alone treatment phases

${ }^{b}$ Geometric mean

\subsubsection{OC Interaction Study}

Two subjects $(6.1 \%)$ withdrew prematurely from this study because of AEs (gastroenteritis and upper respiratory infection), one (3.0 \%) because of the physician's decision, and three $(9.1 \%$ ) because of a protocol deviation. Eighteen subjects $(54.5 \%)$ reported one or more AE: $16(48.5 \%)$ taking OC only and eight $(26.7 \%)$ on co-administration with fostamatinib. Only one AE (gastroenteritis) was considered potentially treatment related [reported for one subject $(3.3 \%)$ receiving combination treatment].

\subsubsection{Warfarin Interaction Study}

No discontinuations due to an $\mathrm{AE}$ or other significant AEs were reported. Six AEs were reported for five subjects $(33.3 \%)$.

\subsubsection{Statin Interaction Study}

Two subjects were withdrawn from the simvastatin group because of AEs: one of influenza and one increased alanine aminotransferase, judged moderate or mild in intensity and not causally related to investigational treatment. There were no clinically relevant trends observed in the frequency of individual AEs for any treatment.

\section{Discussion}

It is important to establish whether co-administration of fostamatinib affects the pharmacokinetics of other drugs with overlapping metabolic pathways. Patients with RA often experience co-morbidities that require polypharmacy [10-13]. Fostamatinib and R406 inhibit a range of proteins, including BCRP, OATP1B1 (data on file), UGTs, and CYP3A4 [1], which are integral to the transport and metabolism of several widely prescribed drugs. The present studies aimed to determine the influence of fostamatinib co-administration on the pharmacokinetics of OC, warfarin, and the HMG-CoA reductase inhibitors rosuvastatin and simvastatin.

In the OC study, a possible explanation of the observed increase in ethinyl estradiol exposure is inhibition of CYP3A4, BCRP, or UGT1A1 by R406. Reduced exposure to $\mathrm{LH}$ and FSH, possibly reflecting reduced secretion of these hormones, is consistent with the observed increase in ethinyl estradiol, and there would appear to be no increased risk of pregnancy due to OC failure. Any increased risk of thrombotic AEs caused by increased exposure to estrogen due to co-administration of Microgynon ${ }^{\circledR} 30$ (which contains $30 \mu \mathrm{g}$ of ethinyl estradiol) with fostamatinib would appear to be modest, as the exposure to ethinyl estradiol is less than that following ethinyl estradiol $50 \mu \mathrm{g}$. 


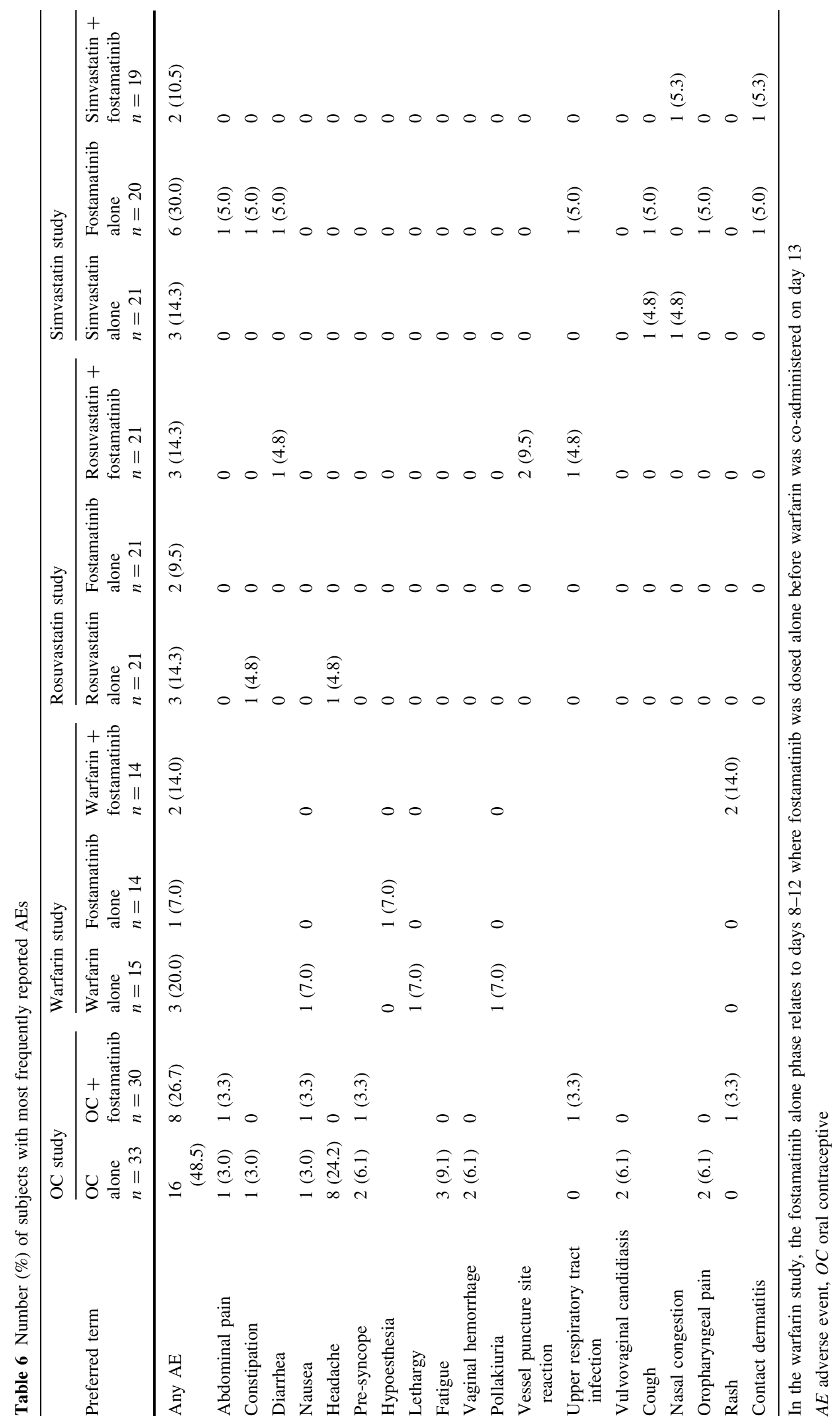


In the warfarin study, geometric mean $R$ - and $S$-warfarin AUC trended upward with the combination treatment. Even so, the CIs surrounding the fostamatinibinduced differences for $R$ - and $S$-warfarin both remained within the interval for non-significance (90\% CI -20.0 to 25.0$)$. The $18 \%$ increase in $R$-warfarin AUC could be attributable in part to the weak inhibitory effects of R406 on CYP3A4 observed in vitro. Furthermore, while quantifiable pre-dose $R$ - and $S$-warfarin concentrations of less than $5 \%$ of $C_{\max }$ pose some minimal bias, the prolonged $t_{1 / 2 \lambda \mathrm{z}}$ (approximately $6 \mathrm{~h}$ ) suggests that these were unlikely the sole source of the observed increase in exposure. There were no differences in the mean $C_{\max }$ for $R$ - and $S$ warfarin. Moreover, the small changes in warfarin pharmacokinetic parameters did not translate into changes in INR.

Increases in AUC and $C_{\max }$ were also demonstrated for rosuvastatin and simvastatin when co-administered with fostamatinib. Rosuvastatin is a substrate of the efflux transporter BCRP, which is responsible for restricting its absorption to $50 \%[24,31]$. Therefore, the interaction is likely a result of inhibition of intestinal BCRP by fostamatinib (R788 and R406), leading to increased absorption (from 50 to $100 \%$, i.e., a doubling of AUC); this is supported by the finding that the distribution and elimination phases of the pharmacokinetic profiles were parallel, indicating no change to biliary or renal elimination pathways. Based on predictions using mechanistic static equations and estimated unbound hepatic inlet concentration of R406, the observed increase in rosuvastatin exposure is unlikely to be a result of inhibition of OATP1B1 $(R$ value $=1.01)$. The increase in simvastatin (lactone) exposure is likely a result of inhibition of intestinal BCRP by fostamatinib (R788 or R406), but may also in part be due to inhibition of CYP3A4 by R406, as simvastatin lactone is a substrate of both [32, 33]. Furthermore, for some subjects, maximum rosuvastatin and simvastatin $C_{\max }$ occurred at the first time point. Therefore, it is possible that the reported values of $C_{\max }$ underestimate the increase in absorption. Statins lower low-density lipoprotein cholesterol, and some AEs associated with statins, such as myopathy, are dose related [34]. Vigilance is recommended upon co-administration with fostamatinib due to the increased statin exposure, and clinicians may consider appropriate monitoring for AEs and/or statin dose reduction where necessary.

Fostamatinib also increased exposure to simvastatin acid. Because R406 is unlikely to inhibit OATP1B1 in vivo, the increase in simvastatin acid exposure may be a consequence of a greater conversion of the lactone to the acid form as a result of higher simvastatin lactone concentrations in the presence of fostamatinib, or may be a result of inhibition of CYP3A4 and/or UGT1A1 by R406. It is also possible that the increased simvastatin exposure was related to a decrease in the volume of distribution secondary to transporter inhibition [35].

In both the OC and warfarin studies, R406 mean concentrations and estimated pharmacokinetic parameters were within a range similar to those previously observed after fostamatinib 100-mg bid dosing. However, R406 exposures were slightly higher (by $\approx 10 \%$ ) in the statin study when fostamatinib was combined with either rosuvastatin or simvastatin. The mechanism of these modest increases in exposure is unknown.

\section{Conclusion}

Clinical investigation revealed that co-administration of fostamatinib $100 \mathrm{mg}$ bid with OC increased exposure to ethinyl estradiol, but not levonorgestrel. Fostamatinib coadministration did not affect the pharmacokinetics or pharmacodynamics of warfarin to a clinically relevant extent, although multiple dosing of fostamatinib resulted in upward trends in AUC for both $R$ - and $S$-warfarin. Changes in statin pharmacokinetics were observed when fostamatinib was co-administered with either rosuvastatin or simvastatin: exposure to rosuvastatin, and simvastatin and simvastatin acid, respectively, was increased. Fostamatinib exhibits drug-drug interactions when co-administered with OC, simvastatin, or rosuvastatin, with the AUC of the latter almost doubling. The action of warfarin is unlikely to be influenced by co-administration with fostamatinib. Fostamatinib was well tolerated in all three studies, with no new safety concerns identified.

Compliance with Ethical Standards Paul Martin, Michael Gillen, Robert Elsby, and Stuart Oliver are full-time employees of AstraZeneca and hold stocks/shares in AstraZeneca. Clive Brealey is an exfull-time employee of AstraZeneca and hold stocks/shares in AstraZeneca. Dominic Surry is an ex-full-time employee of AstraZeneca. David Mathews and James Ritter are employees of Quintiles. This study was sponsored by AstraZeneca. We acknowledge the editorial services of Shelley Lindley, $\mathrm{PhD}$, and Safeer Mughal, PhD, from PAREXEL, which were funded by AstraZeneca. We acknowledge the bioanalytical support provided by Covance lead Paul Severin. Victoria Holmes is an employee of AstraZeneca and hold stocks/shares in AstraZeneca Paul Severin is an employee of Covance.

Open Access This article is distributed under the terms of the Creative Commons Attribution-NonCommercial 4.0 International License (http://creativecommons.org/licenses/by-nc/4.0/), which permits any noncommercial use, distribution, and reproduction in any medium, provided you give appropriate credit to the original author(s) and the source, provide a link to the Creative Commons license, and indicate if changes were made. 


\section{References}

1. Sweeny DJ, Li W, Clough J, et al. Metabolism of fostamatinib, the oral methylene phosphate prodrug of the spleen tyrosine kinase inhibitor R406 in humans: contribution of hepatic and gut bacterial processes to the overall biotransformation. Drug Metab Dispos. 2010;38:1166-76.

2. Weinblatt ME, Kavanaugh A, Burgos-Vargas R, et al. Treatment of rheumatoid arthritis with a Syk kinase inhibitor: a twelveweek, randomized, placebo-controlled trial. Arthritis Rheum. 2008;58:3309-18.

3. Genovese MC, Kavanaugh A, Weinblatt ME, et al. An oral Syk kinase inhibitor in the treatment of rheumatoid arthritis: a threemonth randomized, placebo-controlled, phase II study in patients with active rheumatoid arthritis that did not respond to biologic agents. Arthritis Rheum. 2011;63:337-45.

4. Genovese MC, van der Heijde DM, Keystone EC, et al. A phase III, multicenter, randomized, double-blind, placebo-controlled, parallel-group study of 2 dosing regimens of fostamatinib in patients with rheumatoid arthritis with an inadequate response to a tumor necrosis factor-alpha antagonist. J Rheumatol. 2014;41:2120-8.

5. Taylor PC, Genovese MC, Greenwood M, et al. OSKIRA-4: a phase IIb randomised, placebo-controlled study of the efficacy and safety of fostamatinib monotherapy. Ann Rheum Dis. 2014 (Epub ahead of print).

6. Weinblatt ME, Genovese MC, Ho M, et al. Effects of fostamatinib, an oral spleen tyrosine kinase inhibitor, in rheumatoid arthritis patients with an inadequate response to methotrexate: results from a phase III, multicenter, randomized, double-blind, placebo-controlled, parallel-group study. Arthritis Rheumatol. 2014;66:3255-64.

7. Rigel to focus on ITP, DLE and dry eye strategy provides multiple paths to phase 3/NDA in next 2-3 years. Rigel web site. http://ir.rigel.com/phoenix.zhtml?c=120936\&p=irol-newsArticle \&id=1852213. Accessed 5 March 2014.

8. Fostamatinib (R788)—ITP. Rigel web site. http://www.rigel. com/rigel/ITP. Accessed 5 March 2014.

9. Rigel. Fostamatinib-IgAN. Rigel web site. http://www.rigel. com/rigel/IgAN. Accessed 17 Oct 2014.

10. Briggs AM, March L, Lassere M, et al. Baseline comorbidities in a population-based cohort of rheumatoid arthritis patients receiving biological therapy: data from the Australian rheumatology association database. Int J Rheumatol. 2009;2009:861481.

11. Turesson C, Jacobsson LT, Matteson EL. Cardiovascular co-morbidity in rheumatic diseases. Vasc Health Risk Manag. 2008;4:605-14.

12. Nurmohamed MT. Cardiovascular risk in rheumatoid arthritis. Autoimmun Rev. 2009;8:663-7.

13. Treharne GJ, Douglas KM, Iwaszko J, et al. Polypharmacy among people with rheumatoid arthritis: the role of age, disease duration and comorbidity. Musculoskeletal Care. 2007;5:175-90.

14. Williams JA, Ring BJ, Cantrell VE, et al. Differential modulation of UDP-glucuronosyltransferase 1A1 (UGT1A1)-catalyzed estradiol-3-glucuronidation by the addition of UGT1A1 substrates and other compounds to human liver microsomes. Drug Metab Dispos. 2002;30:1266-73.

15. Silman AJ, Hochberg MC. Epidemiology of the rheumatic diseases. 2nd ed. New York: Oxford University Press; 2001.

16. Centers for Disease Control and Prevention. Arthritis: NHIS Arthritis Surveillance. CDC website. http://www.cdc.gov/ arthritis/data_statistics/national_nhis.htm. Accessed 17 Dec 2013.

17. Kuruvilla M, Gurk-Turner C. A review of warfarin dosing and monitoring. Proc (Bayl Univ Med Cent). 2001;14:305-6.

18. Kim SY, Kang JY, Hartman JH, et al. Metabolism of R- and S-warfarin by CYP2C19 into four hydroxywarfarins. Drug Metab Lett. 2012;6:157-64.
19. Lane S, Al-Zubiedi S, Hatch E, et al. The population pharmacokinetics of R- and S-warfarin: effect of genetic and clinical factors. Br J Clin Pharmacol. 2012;73:66-76.

20. Ballantyne CM, Hoogeveen RC, Raya JL, et al. Efficacy, safety and effect on biomarkers related to cholesterol and lipoprotein metabolism of rosuvastatin 10 or $20 \mathrm{mg}$ plus ezetimibe $10 \mathrm{mg}$ vs. simvastatin 40 or $80 \mathrm{mg}$ plus ezetimibe $10 \mathrm{mg}$ in high-risk patients: results of the GRAVITY randomized study. Atherosclerosis. 2014;232:86-93.

21. CRESTOR (rosuvastatin) [Summary of Product Characteristics]. Luton, UK: AstraZeneca UK Ltd. https://www.medicines.org.uk/ emc/medicine/11976, 2013. Accessed 4 Mar 2015.

22. ZOCOR (simvastatin) [Summary of Product Characteristics]. Hertfordshire, UK: Merck Sharp \& Dohme Limited. https://www. medicines.org.uk/emc/medicine/1201, 2013. Accessed 4 Mar 2015.

23. Elsby R, Hilgendorf C, Fenner K. Understanding the critical disposition pathways of statins to assess drug-drug interaction risk during drug development: it's not just about OATP1B1. Clin Pharmacol Ther. 2012;92:584-98.

24. Keskitalo JE, Zolk O, Fromm MF, et al. ABCG2 polymorphism markedly affects the pharmacokinetics of atorvastatin and rosuvastatin. Clin Pharmacol Ther. 2009;86:197-203.

25. Lee E, Ryan S, Birmingham B, et al. Rosuvastatin pharmacokinetics and pharmacogenetics in white and Asian subjects residing in the same environment. Clin Pharmacol Ther. 2005;78:330-41.

26. Pasanen MK, Neuvonen M, Neuvonen PJ, et al. SLCO1B1 polymorphism markedly affects the pharmacokinetics of simvastatin acid. Pharmacogenet Genomics. 2006;16:873-9.

27. Niemi M, Pasanen MK, Neuvonen PJ. Organic anion transporting polypeptide 1B1: a genetically polymorphic transporter of major importance for hepatic drug uptake. Pharmacol Rev. 2011;63: $157-81$.

28. Center for Drug Evaluation and Research (CDER). Guidance for industry. Drug interaction studies - study design, data analysis, implications for dosing, and labeling recommendations. U S Food and Drug Administration website. http://www.fda.gov/ downloads/Drugs/GuidanceComplianceRegulatoryInformation/ Guidances/UCM292362.pdf Accessed 22 Oct 2012.

29. World Medical Association declaration of Helsinki. Recommendations guiding physicians in biomedical research involving human subjects. JAMA. 1997;277:925-6.

30. International Conference on Harmonisation of Technical Requirements for Registration of Pharmaceuticals for Human Use. ICH harmonised tripartite guideline: guideline for good clinical practice E6(R1). International Conference on Harmonisation website. http://www.ich.org/fileadmin/Public_Web_Site/ ICH_Products/Guidelines/Efficacy/E6_R1/Step4/E6_R1_Guideline. pdf. Accessed 25 Mar 2014.

31. Martin PD, Warwick MJ, Dane AL, et al. Absolute oral bioavailability of rosuvastatin in healthy white adult male volunteers. Clin Ther. 2003;25:2553-63.

32. Keskitalo JE, Pasanen MK, Neuvonen PJ, et al. Different effects of the ABCG2 c.421C>A SNP on the pharmacokinetics of fluvastatin, pravastatin and simvastatin. Pharmacogenomics. 2009;10:1617-24.

33. Lilja JJ, Neuvonen M, Neuvonen PJ. Effects of regular consumption of grapefruit juice on the pharmacokinetics of simvastatin. Br J Clin Pharmacol. 2004;58:56-60.

34. Alla VM, Agrawal V, DeNazareth A, et al. A reappraisal of the risks and benefits of treating to target with cholesterol lowering drugs. Drugs. 2013;73:1025-54.

35. Grover A, Benet LZ. Effects of drug transporters on volume of distribution. AAPS J. 2009;11:250-61. 